\title{
Über Balkan-Slang und die Zukunft der Pflege
}

\section{Eberhard Wolff}

PD Dr. rer. soc., Redaktor Kultur, Geschichte, Gesellschaft

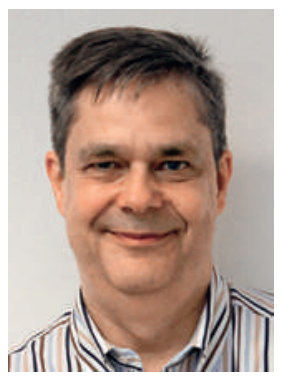

Als ich neulich in Berlin einen Döner «mit allem» bestellte, fragte mich der Verkäufer gleich, ob ich «aus dem Westen" komme (das ist die alte West-Berliner Bezeichnung für alle nicht-berlinerischen Deutschen). Richtig sei nämlich, den Döner «mit alles» zu bestellen. Irgendwie hat er recht damit. Wenn ich am Döner-Stand mit meinem Duden-Deutsch den Verdacht errege, dass ich kein Döner-Deutsch kann, bin ich dort der schlecht integrierte Fremde. Irgendwie hat er damit aber auch nicht recht. Wenn ich das Döner-Deutsch kenne und mich mit meinem Duden-Deutsch am Stand als «aus dem Westen» outen will, dann ist das doch nicht einfach falsch, oder? Aber es ist noch viel komplizierter.

Deutschschweizer Schulhöfe und andere Jugend-Orte werden seit einigen Jahren vom Balkan-Slang beschallt. In diesem Jargon sprechen auch die Kids ohne BalkanHintergrund. Nicht zufällig wurde 2009 das spontane balkanoide Party-Zitat S Beschte wos je hets gits via Telebasel zum Schweizer Jugendwort des Jahres.

Balkan-Deutsch ist ein sogenannter Ethnolekt [1]. Sprachlernende Immigranten sprechen zunächst den «primären Ethnolekt». Wenn sie - oder ihre Kinder die Landessprache schon besser beherrschen und den Ethno-Slang zum Beispiel auf dem Schulhof mehr oder weniger gezielt als Modus wählen, vielleicht sogar parodistisch, ist das ein sogenannter "sekundärer Ethnolekt». Wenn eingeborene Schweizer Jugendliche diese Sprechweise dann übernehmen, ist es ein «tertiärer Ethnolekt».

Kürzlich kam mir am Esstisch die spontane Idee, die anwesenden Teens zu fragen, ob sie diesen Jargon auch könnten. Sie konnten. Klick, und sie waren im tertiären Ethnolekt. Im Fall voll krass, Mann! (Den Rest lasse ich aus Gründen der Schicklichkeit hier besser weg.) Und klick, waren sie wieder draussen. Die Heranwachsenden der geneigten Leserschaft dieser Zeilen dürften eine solche Sprachkompetenz auch ihr eigen nennen. Fragen Sie mal! Meine Teens gaben mir gleich noch grammatikalische Regeln mit auf den Weg: Machst einfach dem Artikel falsch oder machst Artikel weg. Die Grenzen zwischen einem Jargon, seinem Klischee und seiner Selbstparodie sind übrigens fliessend.

Neulich im vollen Bus. In der Vierer-Nische ist noch ein Platz frei. Den Rest besetzen drei von diesen cool-har- ten Jungs mit gerade mal 15 oder 16 Jahren. Sie reden. Härtesten Balkan-Slang. Ich tippe auf den sekundären Ethnolekt der «Secondos», nicht den primären. Einer hält den freien Platz etwas breitbeinig belegt. Ich atme durch und erobere ihn mir vorsichtig. Aber es kommt kein Wosch mir vo dr Siite afigge, Mann? Der Junge rückt wie selbstverständlich zur Seite.

Die harten Jungs reden über das, was sie kürzlich erlebt haben. Im Balkan-Slang tönt alles extrem. Ächt krass wonich bin gsi! Oder so ähnlich. Der Balkan-Slang sträubt sich dagegen, in Buchstaben eingesperrt zu werden. Wovon reden sie? Schule schwänzen? Streit um Mädchen? Eine Beleidigung der Sorte Dini Mueter ...? Velos stehlen oder Schlimmeres? Beim Balkan-Slang kommen unwillkürlich Bilder in den Kopf, die uns nicht nur Plakatkampagnen gegen Immigranten in den letzten Jahren einoperieren wollten.

Ich höre genauer hin. Der Wortführer erzählt eine extreme Geschichte. Es geht um eine Frau. Er hat sie getragen. Und auf einen Stuhl gesetzt. Und dann Wasser über den Kopf ... 'Chschwörsmann!

Die Kollegen wollen es ganz genau wissen. Er erzählt ihnen, wie er eine alte, gebrechliche Frau geduscht hat. Ja, auf den Stuhl setzen, die Dusche von oben hinhalten und dann ... der Rest geht irgendwie im Buslärm unter.

Die Erlebnisse sprudeln geradezu aus dem jungen Mann heraus. Es wird ein Pflege-Praktikum oder so etwas gewesen sein. Er erzählt von denen, mit denen er beim Essen immer am Tisch sitzt. «Mente?», fragt einer nach, der ein Wort nicht versteht. Demente, kennsch nöt? Die wo hent wie Alzheimer, weisch? Er erzählt, wie beim Essen alle Dementen an einem Tisch zusammensitzen. Das hat er gern. Die sind gut drauf. Immer freundlich. Da ist es am lustigsten.

Der Bus hält. Ich muss aussteigen und denke an das sogenannte Balkan-Machotum. Tritt das auch primär, sekundär oder tertiär auf? Wenn ich dann mal dement bin, ist dieser junge Mann als Pfleger vielleicht nicht die schlechteste Wahl. 'Chschwörsmann!

1 Schmid S, Tissot F, Galliker E. «S Beschte wos je hets gits» oder wenn sich Schweizerdeutsch und Migrationssprachen treffen. Schweizerdeutsch. 2010; 18(1):11-4. www.ch-spraach.ch/ethnolekt 